\title{
MEASURING MONETARY POLICY SHOCKS IN FRANCE, GERMANY AND ITALY: THE ROLE OF THE EXCHANGE RATE
}

by

Frank Smets

June 1997

BANK FOR INTERNATIONAL SETTLEMENTS

Monetary and Economic Department

BASLE 
BIS Working Papers are written by members of the Monetary and Economic Department of the Bank for International Settlements, and from time to time by outside economists, and are published by the Bank. The papers are on subjects of topical interest and are technical in character. The views expressed in them are those of their authors and not necessarily the views of the BIS.

(C) Bank for International Settlements 1997

CH-4002 Basle, Switzerland

Also available on the BIS World Wide Web site (http://www.bis.org).

All rights reserved. Brief excerpts may be reproduced or translated provided the source is stated.

ISSN 1020-0959 


\title{
MEASURING MONETARY POLICY SHOCKS IN FRANCE, GERMANY AND ITALY: THE ROLE OF THE EXCHANGE RATE
}

by

Frank Smets

June 1997

\begin{abstract}
In the identified VAR literature the role of the exchange rate in measuring monetary policy shocks has often been neglected. However, many open economies find it useful to target the exchange rate. In such a regime exchange rate innovations will better capture domestic monetary policy shocks. This paper first estimates the weight on the ECU exchange rate in France, Germany and Italy under the ERM regime. Next, these weights are used to identify a typical monetary policy shock in these countries and analyse its effects on output, inflation, the interest rate and the exchange rate.
\end{abstract}

JEL: E3-E4-E5

I would like to thank Daniele Terlizzesse and seminar participants at the BIS, the European Economic Association Meetings in Istanbul, the joint CEPR-Banca d'Italia workshop on "Model Specification, Identification and Estimation in Empirical Macroeconomics" and the Annual Meeting of the Swiss Society of Statistics and Economics for helpful comments on an earlier paper, entitled "Measuring monetary policy in the G-7 countries: interest rates versus exchange rates". 



\section{Contents}

Introduction

1. Incorporating the exchange rate in a structural VAR .................................. 3

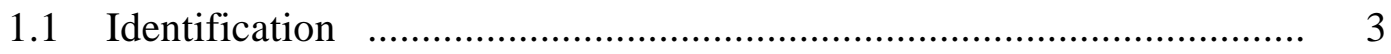

2. The weight on the ECU exchange rate in France, Germany and Italy ........... 6

2.1 The monetary policy regime …...................................................... 6

2.2 Estimating the weight on the ECU exchange rate ............................ 7

3. Comparing the effects of monetary policy in France, Germany and Italy $\quad \ldots . . . \quad 9$

3.1 Monetary policy shocks f.............................................................. 9

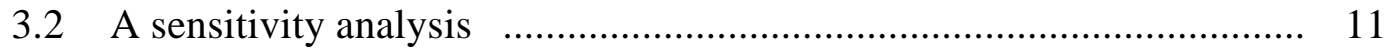

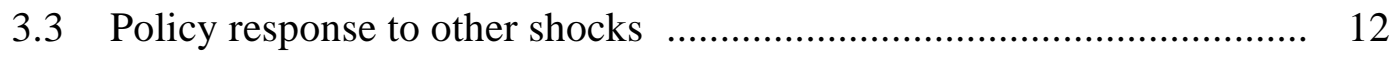

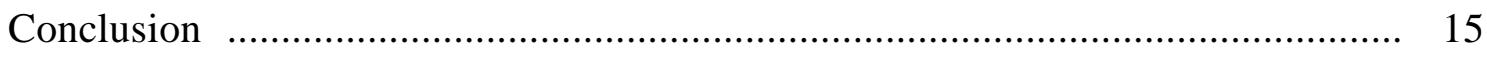

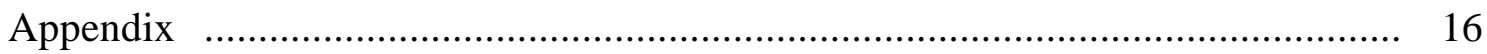

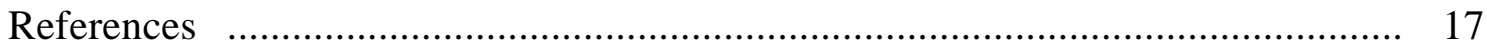





\section{Introduction}

In the extensive literature on measuring monetary policy shocks using identified vector autoregressions (VARs), the exchange rate has typically been omitted from the analysis. ${ }^{1}$ While the neglect of the exchange rate may be justified for a large, relatively closed economy like the United States, the exchange rate plays a prominent role in more open economies. Indeed, many countries, including those that participate in the exchange rate mechanism (ERM) of the European Monetary System, find it useful to target the exchange rate. In such a regime domestic monetary policy shocks will be mainly reflected in exchange rate innovations. More generally, monetary authorities in open economies may offset some of the contemporaneous exchange rate shocks they face because these shocks significantly affect the economy, again suggesting a role for the exchange rate in the measurement of the policy stance. ${ }^{2}$

This paper focuses on the role of the ECU exchange rate in the monetary policy strategy of France, Germany and Italy. Two factors suggest the importance of the ECU exchange rate in these countries. First, France, Germany and Italy are considerably more open than the US economy, in particular with respect to other European countries, and, second, they have participated in the ERM since its inception in March 1979. Originally the ERM was established as a symmetric system in which each participant would peg its exchange rate against the ECU, defined as a basket of EC currencies. De facto, Germany became the anchor country of the system, thereby setting monetary policy for the ERM area as a whole. ${ }^{3}$ This asymmetry between Germany and the other ERM countries suggests that the role of the ECU exchange rate in measuring domestic monetary policy innovations may be smaller in Germany than in France and Italy.

Including an exchange rate in the VAR analysis complicates the identification problem because there is no obvious contemporaneous zero restriction that allows the researcher to distinguish between interest rate and exchange rate innovations that are the result of domestic monetary policy shocks and those that are due to the monetary authorities' response to shocks to the exchange rate arising from speculative pressures, changes in the risk premium or foreign interest rate changes. In this paper I follow Smets (1996) and use the weight on the exchange rate in the short-run reaction

1 See, for example, Bernanke and Blinder (1992), Strongin (1992) and Christiano et al. (1994). A recent paper which uses a model of the money market and central bank operating procedures to test the different proposed identification schemes is Bernanke and Mihov (1996).

2 This notion has inspired a number of central banks (e.g. the Bank of Canada and the Reserve Bank of New Zealand) to use a monetary conditions index (MCI) as operating target. The MCI is a weighted average of a short-term interest rate and a trade-weighted exchange rate and is used to measure changes in the stance of monetary policy in open economies. See Freedman (1993) and, for a recent survey, Gerlach and Smets (1996).

3 This solved the so-called $\mathrm{N}-1$ problem which follows from the fact that with $\mathrm{N}$ currencies participating in a fixed exchange rate regime only $\mathrm{N}-1$ bilateral exchange rates are fixed. For an account of the ERM experience and empirical evidence on the German dominance hypothesis, see Giavazzi and Giovannini (1989), Gros and Thygesen (1992) or De Grauwe (1994). 
function of the monetary authorities to solve this identification problem. The advantage of this strategy is that it is flexible enough to accommodate monetary policy regimes with a different emphasis on the exchange rate. As shown below, explicitly taking these differences into account is crucial for a credible identification of domestic monetary policy shocks and their effects. The disadvantage is that one needs to know the weight on the exchange rate. As there is only imprecise information concerning the role of the ECU exchange rate in the monetary policy strategy of France, Germany and Italy, I empirically estimate this weight over the period since the start of the ERM and various sub-periods and find that these estimates generally conform to what one would have expected on the basis of a description of the monetary policy regimes.

The rest of the paper is structured as follows. Section 1 presents the empirical model and the identification problem. Following Smets (1996), I estimate a four-variable identified VAR model comprising output, prices, a short-term interest rate and the ECU exchange rate. The aim of the VAR analysis is to explain movements in these four endogenous variables in terms of four structural shocks: a supply shock, a demand shock, a domestic monetary policy shock and an exchange rate shock.

In Section 2 I estimate the weight on the ECU exchange rate in France, Germany and Italy during the 1979-96 period using foreign interest rate and exchange rate innovations as instruments. As the emphasis on the exchange rate is likely to have changed over the sample period, estimates for relevant sub-samples are also provided. Estimated over the whole sample period, the weight on the ECU exchange rate is significant in both France and Italy, but not in Germany. In France, the weight is close to one - as would be the case under pure exchange rate targeting - and increases over the sample period as the commitment to the ERM parity firms. In Italy, the weight estimated over the whole period is considerably smaller than in France, partly reflecting the wider exchange rate band in the 1980s, and appears to have fallen during the estimation period. In particular, the estimated weight on the exchange rate is not significantly different from zero in the most recent period starting in September 1992, when the Italian lira was forced out of the ERM. For Germany our estimation strategy is less successful. Although one is unable to reject the hypothesis that the weight on the exchange rate during the estimation period is zero, in this case this finding may be the result of a lack of good instruments.

In Section 3 the estimated weights are then used to identify the monetary policy shocks and their effects on output, prices, the interest rate and the exchange rate. The estimated effects qualitatively conform to what one would expect in a standard open economy model. The effects on output and prices are very similar to what was found in Gerlach and Smets (1995). Moreover, in contrast to the findings in Barran et al. (1996) and Grilli and Roubini (1995), monetary policy shocks lead to an appreciation of the currency in all three countries, so that the so-called exchange rate puzzle 
disappears. ${ }^{4}$ An analysis of the sensitivity of the estimated effects to changes in the assumed weight on the exchange rate confirms that the widely used zero contemporaneous restrictions are not always credible and may lead to econometric misspecification, in particular when dealing with financial prices such as interest rates and exchange rates that are simultaneously determined.

The final section concludes.

\section{Incorporating the exchange rate in a structural VAR}

The identified VAR model is an attempt to explain movements in output, prices, the short-term interest rate and the ECU exchange rate in France, Germany and Italy in terms of four structural shocks: a supply shock, a demand shock, a domestic monetary policy shock and an exchange rate shock. Using standard notation, let $\mathrm{x}_{\mathrm{t}}^{\mathrm{T}}=\left[\begin{array}{llll}\Delta \mathrm{y}_{\mathrm{t}} & \Delta \mathrm{p}_{\mathrm{t}} & \mathrm{R}_{\mathrm{t}} & \Delta \mathrm{e}_{\mathrm{t}}\end{array}\right]$ be the vector of stationary endogenous variables, with $\Delta \mathrm{y}_{\mathrm{t}}$ denoting output growth, $\Delta \mathrm{p}_{\mathrm{t}}$ the rate of inflation, $\mathrm{R}_{\mathrm{t}}$ the domestic nominal short-term interest rate and $\Delta e_{t}$ the rate of appreciation of the nominal ECU exchange rate. ${ }^{5}$ Furthermore, let $\varepsilon_{\mathrm{t}}^{\mathrm{T}}=\left[\begin{array}{llll}\varepsilon_{\mathrm{t}}^{\mathrm{s}} & \varepsilon_{\mathrm{t}}^{\mathrm{d}} & \varepsilon_{\mathrm{t}}^{\mathrm{p}} & \varepsilon_{\mathrm{t}}^{\mathrm{x}}\end{array}\right]$ be the vector of structural shocks, with $\varepsilon_{\mathrm{t}}^{\mathrm{s}}$ denoting a supply shock, $\varepsilon_{\mathrm{t}}^{\mathrm{d}}$ a demand shock, $\varepsilon_{\mathrm{t}}^{\mathrm{p}}$ a unilateral monetary policy shock and $\varepsilon_{\mathrm{t}}^{\mathrm{x}}$ an exchange rate shock.

The reduced form of the structural model can be written as:

$$
\mathrm{x}_{\mathrm{t}}=\mathrm{A}(\mathrm{L}) \varepsilon_{\mathrm{t}}
$$

where the matrix lag polynomial $\mathrm{A}(\mathrm{L})$ contains the responses of the endogenous variables to the underlying structural disturbances.

As usual, the estimation of the structural model in (1) occurs in two steps. In the first step a reduced-form VAR model comprising 12 lags of the endogenous variables is estimated. In the second step a sufficient number of identification restrictions is applied to retrieve the structural shocks from the residuals of the VAR model. Next, I discuss the identification scheme. ${ }^{6}$

\subsection{Identification}

As in Bernanke and Mihov (1995), our identification scheme is block recursive. It allows us to first derive the supply and demand shocks, and then continue with a discussion of the monetary shocks (i.e. policy and exchange rate shocks). However, while in Bernanke and Mihov (1995) the block recursivity follows from the fact that non-policy variables (such as output and prices) are

\footnotetext{
$4 \quad$ See Grilli and Roubini (1996).

5 The definition of each of the series used and their stationarity properties are provided in the Appendix.

6 For a more elaborate exposition of this two-step process, see, for example, Galí (1992) or Gerlach and Smets (1995).
} 
ordered first in a short-run Choleski scheme, I use a mixture of long and short-run zero restrictions, allowing a structural interpretation of the shocks to output and prices.

\section{Supply and demand shocks}

To distinguish the supply and demand shocks from the monetary shocks, an extended version of the Gerlach and Smets (1995) identification scheme is used. ${ }^{7}$ I rely on a vertical long-run Phillips curve to assume that demand and monetary shocks have no long-run impact on the level of real output. Supply shocks are thus associated with the permanent shocks to output. Demand shocks are distinguished from monetary shocks by the widely used assumption that the latter do not contemporaneously affect real output. These long and short-run restrictions, which can be summarised as $\mathrm{A}_{12}(1)=\mathrm{A}_{13}(1)=\mathrm{A}_{14}(1)=0$ and $\mathrm{A}_{13}(0)=\mathrm{A}_{14}(0)=0$, together with the usual restrictions that the shocks have a unit variance and are independent, allow us to estimate the supply and demand shocks and their impact on the policy variables, that is, the short-term interest rate and the exchange rate.

\section{Monetary policy and exchange rate shocks}

The focus of this paper is on the identification of the two monetary shocks. Once the effects of supply and demand shocks on the interest rate and the exchange rate have been removed, the short-run reduced-form empirical model of monetary policy behaviour and the foreign exchange market can be written as follows:

$$
u_{t}^{R}=\alpha_{1} \varepsilon_{t}^{\mathrm{p}}+\alpha_{2} \varepsilon_{t}^{\mathrm{x}}
$$

$$
u_{t}^{e}=\beta_{1} \varepsilon_{t}^{p}+\beta_{2} \varepsilon_{t}^{x}
$$

where the left-hand variables are the interest rate and exchange rate residuals respectively.

Equation (2) captures the short-run reaction function of the monetary authorities. It is assumed that the central bank controls the domestic short-term interest rate and that it adjusts this instrument either to unilaterally change the stance of monetary policy $\left(\varepsilon_{\mathrm{t}}^{\mathrm{p}}\right)$ or in response to foreign exchange market disturbances due to adjustments in the risk premium, shifts in exchange rate expectations or foreign interest rate shocks $\left(\varepsilon_{t}^{x}\right)$. Equation (3) can be derived from a foreign exchange market equilibrium condition and states that the current exchange rate also depends on domestic policy innovations and exchange rate shocks.

The model (2) to (3) is under-identified. One needs at least one additional identifying assumption to be able to estimate the policy and exchange rate shocks. In the next subsection a general identification strategy based on Smets (1996) is presented.

\footnotetext{
7 This scheme is in turn based on Galí (1992).
} 


\section{Policy shocks and the weight on the exchange rate}

Solving the model (2) to (3) for the monetary policy shock in terms of the reduced-form interest rate and exchange rate residuals and renormalising the policy shock such that the sum of the weights on the domestic interest rate and exchange rate residuals is one results in the following expression:

$$
\varepsilon_{t}^{\mathrm{p}}=(1-\omega) \mathrm{u}_{\mathrm{t}}^{\mathrm{R}}+\omega \mathrm{u}_{\mathrm{t}}^{\mathrm{e}}
$$

Equation (4) can be interpreted as a short-run monetary conditions index (MCI). ${ }^{8}$ The relative weight of the exchange rate in the MCI is given by $\omega=-\alpha_{2} /\left(\beta_{2}-\alpha_{2}\right)$. Since in a successful identification scheme one would expect $\alpha_{2}$, which captures the effect of exchange rate shocks on the domestic interest rate, to be non-positive (an appreciation of the exchange rate leads to a fall in policy rates) and $\beta_{2}$ to be positive, this weight should lie between zero and one.

If the value of $\omega$ were known, then the identification problem would be solved as one can define the policy shock according to (4). ${ }^{9}$ The main advantage of focusing on this weight to identify policy shocks is that it encompasses not only the two extreme cases of interest and exchange rate targeting but also the intermediate cases, and therefore allows for a more general and flexible approach to identifying policy shocks in an open economy.

The interest rate targeting regime corresponds to a weight of zero on the exchange rate $(\omega=0)$ and is equivalent to a neglect of exchange rate shocks in the short-run reaction function of the monetary authorities $\left(\alpha_{2}=0\right)$. Eichenbaum and Evans (1995) use this assumption to analyse the impact of a monetary policy shock on various bilateral exchange rates in the United States.

The opposite extreme of exchange rate targeting may be appropriate for small open economies which use the exchange rate as their operating target. Such a regime existed, for example, in New Zealand from 1988 until 1996. ${ }^{10}$ It also applies to countries that operate under an adjustable peg regime such as France and Italy. ${ }^{11}$ In both cases policy rates will respond very strongly to pressures on the exchange rate arising from, for instance, speculative capital flows. As a result $\alpha_{2}$, will be very large in absolute value. In the extreme case of pure exchange rate targeting $(\omega=1)$, there

8 See footnote 2.

9 The actual implementation of the identification scheme is discussed in the appendix of Smets (1996).

10 Every quarter, when the new inflation projections were made, the Reserve Bank of New Zealand set a comfort zone for the exchange rate which was consistent with achieving its inflation target of 0-2 \% over the next year. See Grimes and Wong (1994). Since the end of 1996 the focus has changed to an MCI, with a weight on the exchange rate of one to two.

11 One difference between an adjustable peg regime and the use of the exchange rate as operating target under a floating exchange rate regime is that in the former case there is a much more limited scope to change the desired target, for example to adjust to supply and demand shocks. 
will be a one-to-one correspondence between domestic monetary policy shocks and exchange rate innovations as the central bank will not allow exchange market disturbances to affect the exchange rate $\left(\beta_{2}=0\right)$. By the same token exchange rate shocks will be reflected in large interest rate movements.

Finally, in most open economies with floating exchange rates the central bank's short-run reaction function will most probably correspond to an intermediate case whereby some positive weight is put on the exchange rate. An explicit example is Canada, which since 1987 has been using an MCI with $\omega=0.25$ as operating target. Germany is also likely to fall into this category. In this case the question arises: what is the optimal weight on the exchange rate? Central banks that use MCIs have based the weight on the relative importance of a $1 \%$ effective exchange rate appreciation and a 1 percentage point interest rate rise in affecting aggregate demand. In the case of Canada, a weight of 0.25 is thus derived from the empirical finding that a 1 percentage point interest rate increase has three times as much effect on aggregate demand as a $1 \%$ appreciation of the trade-weighted exchange rate. In Gerlach and Smets (1996), a simple open economy model is discussed in which the weights so determined can be shown to be optimal for a central bank that targets inflation.

Although the focus on $\omega$ is useful to discuss the various identification options, in the case of France, Germany and Italy there is no precise information concerning its actual size apart from a suspicion that it is larger in France and Italy than in Germany. In what follows the strategy is therefore to first estimate the weight and then use that estimate to identify the policy shocks.

\section{The weight on the ECU exchange rate in France, Germany and Italy}

In this section I estimate equation (4) using foreign interest rate and exchange rate shocks as instruments. However, before doing so, I briefly describe changes in the monetary policy regime during the sample period.

\subsection{The monetary policy regime}

All three countries joined the ERM in March 1979. However, as Germany effectively became the anchor country, the exchange rate constraint was less binding for the Bundesbank. In fact, the Bundesbank continued to pursue a policy of monetary growth targeting during the whole ERM period, albeit in a flexible manner. For example, Tsatsaronis (1994) and Clarida and Gertler (1996) found that the Bundesbank responds quite strongly to changes in the DM/dollar exchange rate.

In France and Italy, participation in the ERM implied a stronger policy focus on the exchange rate, although the commitment to the ERM parity has varied over time and between the two countries. Since 1979 the French authorities have pegged their currency in a narrow band of $\pm 2.25 \%$ 
against the other ERM currencies. After the ERM crisis of July 1993 the ERM fluctuation bands were widened to $\pm 15 \%$, but many participating countries, including France, refrained from making full use of this increased exchange rate flexibility. While the period up to 1984 was characterised by frequent readjustments of the ERM parity grid (including several devaluations of the French franc against other ERM currencies), since then the French exchange rate commitment has firmed considerably, with the parity against the Deutsche Mark remaining unchanged since January 1987.

The ERM band for the Italian lira was wider $( \pm 6 \%)$ than that for the French franc until the end of the 1980s. After a brief period of adhering to the narrow fluctuation band of $\pm 2.25 \%$ (January 1990-September 1992), the Italian lira was forced to leave the ERM during the European exchange market crisis of September 1992. In this new regime of floating exchange rates, the policy focus was more directly geared towards inflation and inflation expectations. ${ }^{12}$

This brief description of the policy regimes suggests that one might expect a strong and increasing weight on the ECU exchange rate in France, a lower and, since 1992, falling weight in Italy and a still lower weight in Germany.

\subsection{Estimating the weight on the ECU exchange rate}

In order to obtain an empirical estimate of the weight on the ECU exchange rate during the ERM period, equation (4) is estimated using Hansen's (1982) general method of moments (GMM). For France and Italy, shocks to the US and German short-term interest rates and the DM/dollar exchange rate are used as instruments. ${ }^{13}$ For obvious reasons only the first instrument is available for Germany. For these instruments to be valid, a necessary condition is that foreign interest rate and foreign exchange rate shocks are orthogonal to the policy shocks in (4). As the aim of the paper is to uncover purely domestic policy shocks and it is unlikely that such shocks would affect foreign interest rates or foreign exchange rates, this condition appears to be satisfied. The assumption also holds in the model presented in Gerlach and Smets (1996): foreign interest rate shocks do not affect the optimal MCI. Finally, a similar assumption has been used by Kim and Roubini (1995) in a set of two-country VARs including the United States, and by Clarida and Gertler (1996) in a VAR model for Germany.

Table 1 reports the results of the GMM estimation for each of the countries and for various sub-samples which were identified on the basis of the description of the policy regimes above. For France and Italy the results are quite encouraging. I find that over the whole sample period the estimated weight on the ECU exchange rate is 0.75 in France and 0.38 in Italy. Not surprisingly, the hypothesis of pure interest rate targeting can be rejected in both cases. The hypothesis of pure

12 The Italian lira rejoined the ERM at the very end of our sample period in October 1996.

13 The residuals are obtained by regressing each of the instruments on its own lags, 12 lags of the endogenous variables in system (1) and the estimated supply and demand shocks. 
exchange rate targeting can also be rejected, but only marginally so in the case of France. The difference between France and Italy is smaller when one only considers the period up to the ERM crisis of September 1992 (second row of Table 1). The weight on the ECU exchange rate is 0.66 in France and 0.53 in Italy.

Table 1

Estimates of equation (4): $\varepsilon_{t}^{p}=(1-\omega) u_{t}^{i}+\omega u_{t}^{x}$

\begin{tabular}{|c|c|c|c|c|c|}
\hline & France & & Italy & & Germany \\
\hline Sample & $\omega$ & $\mathrm{J}$ & $\omega$ & $\mathbf{J}$ & $\omega$ \\
\hline 80:03-96:12 & $0.75(0.12)[5.95]$ & 0.04 & $0.38(0.09)[4.05]$ & 0.00 & $1.70(1.65)[1.02]$ \\
\hline 80:03-92:08 & $0.66(0.12)[5.49]$ & 0.05 & $0.53(0.11)[4.50]$ & 0.00 & - \\
\hline 80:03-83:12 & $0.59(0.23)[2.60]$ & 0.09 & $0.80(0.09)[8.37]$ & 0.04 & - \\
\hline 84.01-93:07 & $0.79(0.10)[7.73]$ & 0.00 & - & - & - \\
\hline 83:08-96:12 & $0.84(0.18)[4.53]$ & 0.00 & - & - & - \\
\hline 84:01-92:08 & - & - & $0.33(0.15)[2.20]$ & 0.05 & - \\
\hline 92:09-96:12 & - & - & $0.07(0.08)[0.83]$ & 0.07 & - \\
\hline
\end{tabular}

Equation (4) is estimated using GMM. The instruments used are mentioned in the text. Numbers in brackets refer to the standard error of the estimate () and the related t-statistic []. The J-statistic is distributed as $\chi^{2}(2)$. The critical value for tests at the $5 \%$ level is 5.9 .

The findings are even more interesting if the sample is split into sub-periods. For France, the weight on the ECU exchange rate constantly over the sample period from 0.59 in the early ERM period to 0.84 in the period since the widening of the ERM bands, confirming that, as noted above, there was a firming of the exchange rate commitment. In fact, in the period since 1987 one cannot reject the hypothesis of pure exchange rate targeting, which is consistent with the fact that the French franc parity has not been changed during this period.

In the case of Italy one finds that the weight on the ECU exchange rate has generally fallen over the sample period. Somewhat surprisingly, the estimated weight is higher in the early ERM period (1980:3-1983:12) than in the subsequent ERM period. Consistent with the change in exchange rate regime, the weight on the ECU rate since September 1992 is estimated to be very small and not significantly different from zero. The hypothesis of pure interest rate targeting thus cannot be rejected in this period.

For Germany the results of the estimation are less successful. For completeness they are nevertheless reported in Table 1. The point estimate for Germany proves to be greater than one. However, the standard errors are so large that any weight between zero and one cannot be rejected. In fact, it appears that the only credible instrument available in this case (the US interest rate shock) is 
not a very good one. In what follows I assume that in Germany the weight on the ECU exchange rate is zero. ${ }^{14}$

\section{Comparing the effects of monetary policy in France, Germany and Italy}

In this section I use the empirical weights estimated over the whole sample period to complete the identification of the VAR model discussed in Section 1 and analyse the resulting impulse response functions. To make a cross-country comparison easier, Graphs 1, 3, 4 and 5 combine the responses to a particular shock in each of the three countries. In these graphs each column gives the effect of a shock in a particular country, while each row focuses on the response of a particular endogenous variable. The last row of each graph shows the effect on the real MCI. ${ }^{15}$ Table 2 reports the forecast error variance decomposition.

\subsection{Monetary policy shocks}

Graph 1 reports the effects of a domestic monetary policy shock. In all three countries a tightening of monetary policy is associated with an increase in the real interest rate and a real appreciation of the exchange rate, the combined effects of which are reflected in a rise in the real MCI. This finding is qualitatively consistent with open interest rate parity and shows that the socalled exchange rate puzzle discussed by Grilli and Roubini (1995), whereby a positive interest rate shock leads to a depreciation of the exchange rate in a number of countries, does not arise if one properly takes into account the role of the exchange rate in the monetary policy strategy.

Consistent with what one would expect in a standard open economy aggregate supply and demand model, this tightening leads to a significant fall in industrial production and a gradual fall in prices. Qualitatively, these results are very similar to the findings in Gerlach and Smets (1995). Accordingly, the contribution of policy shocks to output and prices is found to be negligible (Table 2). One exception is the case of France, where policy shocks explain about one-half of the forecast error variance of prices. Policy shocks do explain a significant fraction of the interest rate and exchange rate variability in the three countries. Interestingly, in Germany policy shocks account for about three-quarters of the forecast error in exchange rates.

14 As it turns out, the impulse responses of a policy shock are not very sensitive to the choice of the weight in the case of Germany (see Graph 2).

15 The weight used to calculate the real MCI is 0.25 , which is that used by the International Monetary Fund for these countries. The real interest rate is defined ex ante, that is, using inflation expectations consistent with the VAR model. 
Table 2

\section{Forecast error variance decomposition}

Contribution of:

$\varepsilon^{\mathrm{s}} \quad \varepsilon^{\mathrm{d}} \quad \varepsilon^{\mathrm{p}} \quad \varepsilon^{\mathrm{x}} \quad \varepsilon^{\mathrm{s}} \quad \varepsilon^{\mathrm{d}} \quad \varepsilon^{\mathrm{p}} \quad \varepsilon^{\mathrm{x}} \quad \varepsilon^{\mathrm{s}} \quad \varepsilon^{\mathrm{d}} \quad \varepsilon^{\mathrm{p}} \quad \varepsilon^{\mathrm{x}}$

to:

One-year horizon

Two-year horizon

Four-year horizon

Industrial production

\begin{tabular}{lcccccccccccc}
\hline France & 83 & 10 & 4 & 0 & 88 & 4 & 6 & 0 & 94 & 2 & 2 & 0 \\
Italy & 12 & 75 & 9 & 2 & 24 & 59 & 13 & 3 & 56 & 32 & 8 & 2 \\
Germany & 53 & 37 & 6 & 2 & 65 & 23 & 8 & 2 & 86 & 8 & 3 & 0
\end{tabular}

Consumer prices

\begin{tabular}{lcccccccccccc}
\hline France & 19 & 33 & 46 & 0 & 23 & 23 & 52 & 0 & 28 & 18 & 52 & 0 \\
Italy & 82 & 2 & 9 & 5 & 83 & 5 & 8 & 3 & 82 & 7 & 8 & 2 \\
Germany & 35 & 22 & 8 & 33 & 52 & 30 & 7 & 9 & 59 & 27 & 10 & 1
\end{tabular}

Nominal interest rate

\begin{tabular}{lcccccccccccc}
\hline France & 17 & 24 & 22 & 35 & 17 & 23 & 26 & 33 & 20 & 22 & 27 & 30 \\
Italy & 13 & 11 & 48 & 25 & 23 & 11 & 42 & 22 & 29 & 11 & 39 & 20 \\
Germany & 29 & 53 & 7 & 9 & 41 & 41 & 10 & 7 & 45 & 35 & 12 & 6
\end{tabular}

ECU exchange rate

\begin{tabular}{lcccccccccccc}
\hline France & 16 & 7 & 46 & 29 & 9 & 4 & 43 & 43 & 4 & 3 & 46 & 45 \\
Italy & 11 & 1 & 24 & 62 & 10 & 2 & 22 & 64 & 9 & 2 & 21 & 65 \\
Germany & 14 & 9 & 70 & 4 & 16 & 5 & 75 & 2 & 10 & 4 & 82 & 1
\end{tabular}




\section{The effects of a monetary policy shock}

France
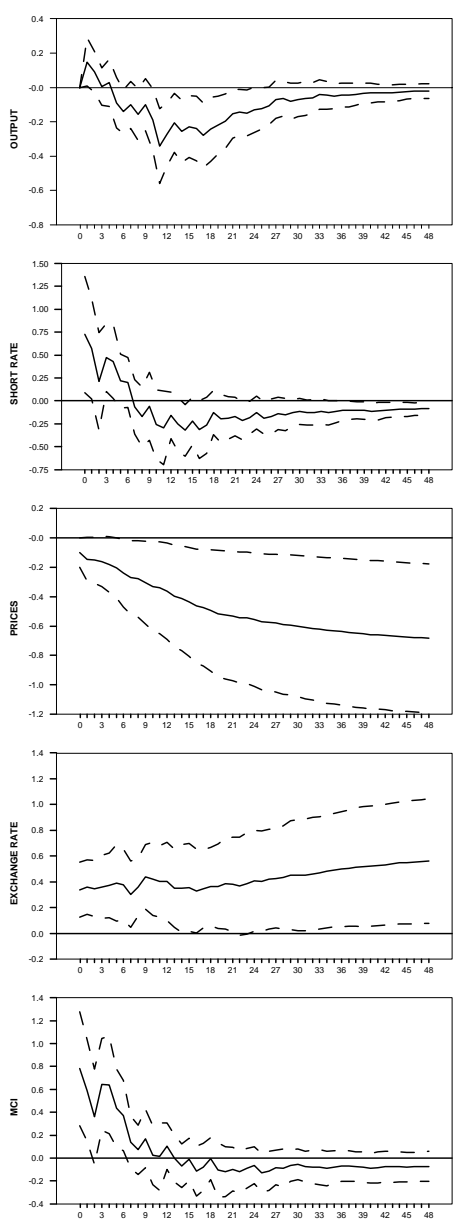

Italy
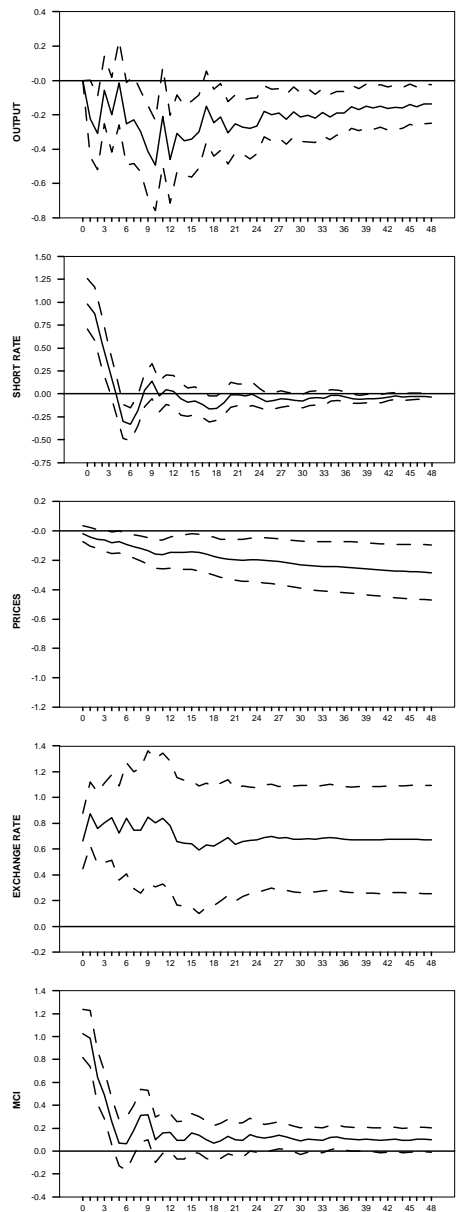

Germany
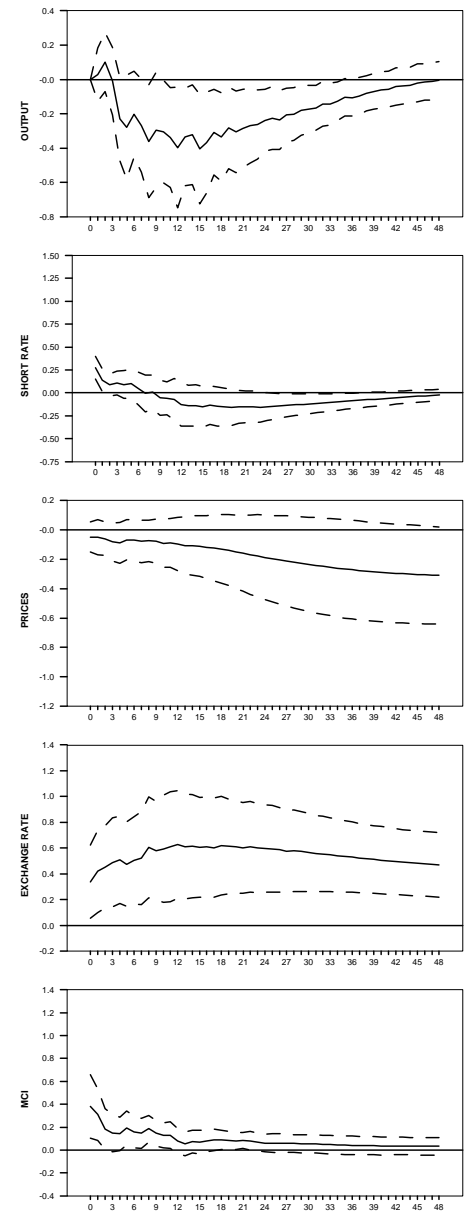

Note: The broken lines are bootstrapped $10 \%$ confidence bands. The definition of the MCI is given in footnote 15 .

\subsection{A sensitivity analysis}

In this subsection the sensitivity of the impulse responses of a monetary policy shock to changes in the assumed short-run weight on the exchange rate is examined. Graph 2 shows the impulse response functions to a so-called monetary policy shock for weights equal to zero (pure interest rate targeting), one (pure exchange rate targeting) and one-half (equal weight on the interest rate and the exchange rate), together with those based on the estimated weights.

Overall, the choice of the weight does not seem to matter much in the case of Germany. The effect of a policy shock on the endogenous variables appears very robust to changes in the weight on the exchange rate from zero to one. A larger sensitivity of the impulse responses can be detected in France and Italy. In both countries the unrealistic assumption of a zero weight on the exchange rate would imply that a domestic policy shock has no significant effect on the exchange rate, which is inconsistent with basic models of exchange rate determination. The effects on the other endogenous 
variables are, however, hardly affected. Assuming the opposite extreme case of exchange rate targeting leads to serious misspecification in Italy, as in that case neither output nor prices are affected by a domestic monetary policy shock. In contrast, in France only the effect on the interest rate is significantly altered. In sum, the sensitivity analysis shows that the choice of the weight on the exchange rate matters for a correct specification of the monetary policy shock and its effects.

Graph 2

Monetary policy shocks and the weight on the exchange rate: a sensitivity analysis

France
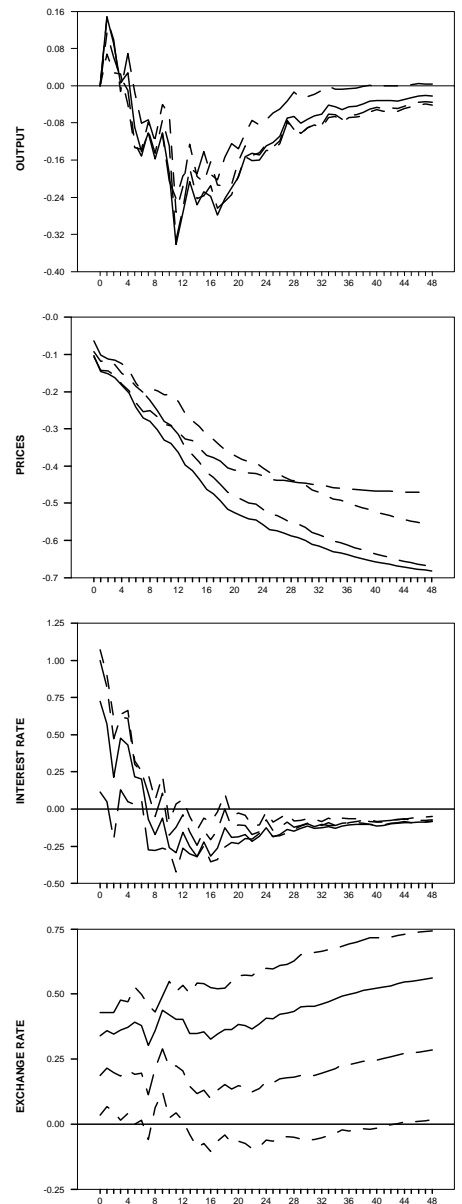

Italy
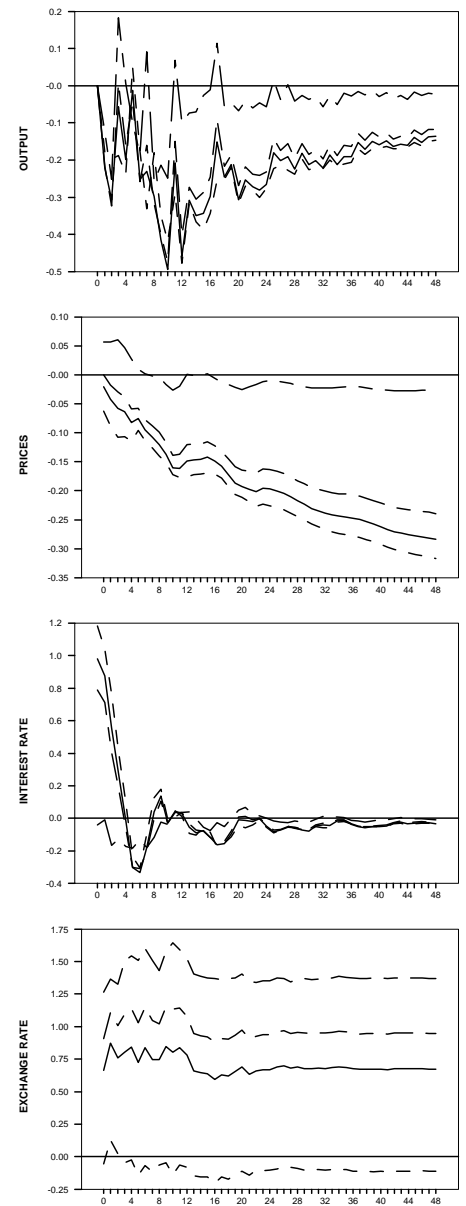

Germany
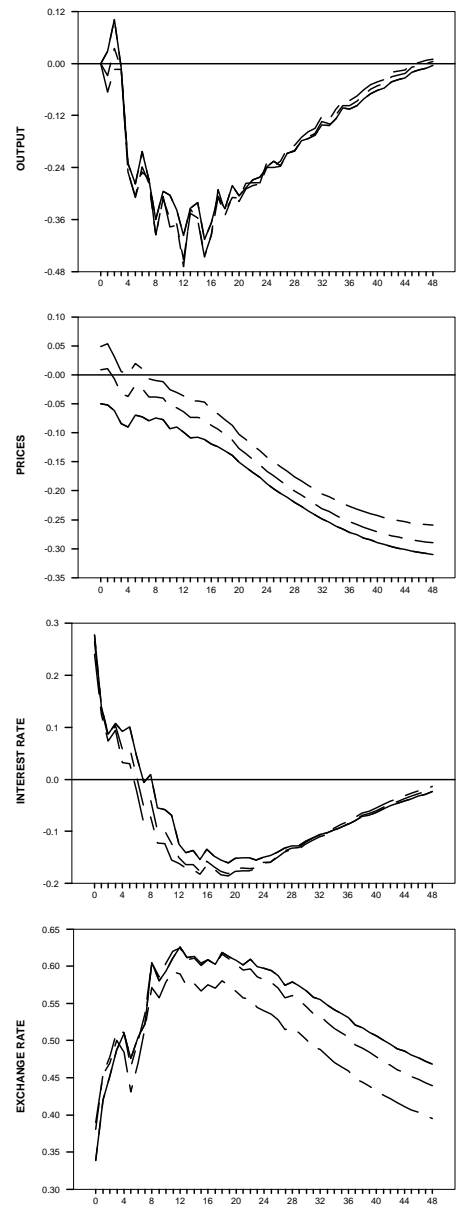

This graph shows the effects of a monetary policy shock on output, prices, the interest rate and the exchange rate for different identification assumptions concerning the weight on the exchange rate (see equation (4)). The solid lines correspond to the estimated weight from Section 2 ( 0.75 for France, 0.38 for Italy and 0.0 for Germany). The short dashes correspond to a weight of zero, while the short-normal and short-long dashes correspond to a weight of 0.5 and 1 respectively.

\subsection{Policy response to other shocks}

Graphs 3 to 5 plot the impulse responses of the endogenous variables to the other shocks.

Graph 3 shows that in France and Italy speculative pressures on the exchange rate result in an 
appreciation of the currency and a fall in interest rates. The net effect of these interest rate and exchange rate movements on real monetary conditions is limited, which may explain the generally insignificant output and price effects of these shocks. In Germany, the main effect of the so-called exchange rate shock is to move prices temporarily higher, suggesting a misspecification which may be due to the fact that this kind of exchange rate shock has not been prevalent in Germany.

Graph 3

\section{The effects of an exchange rate shock}

France
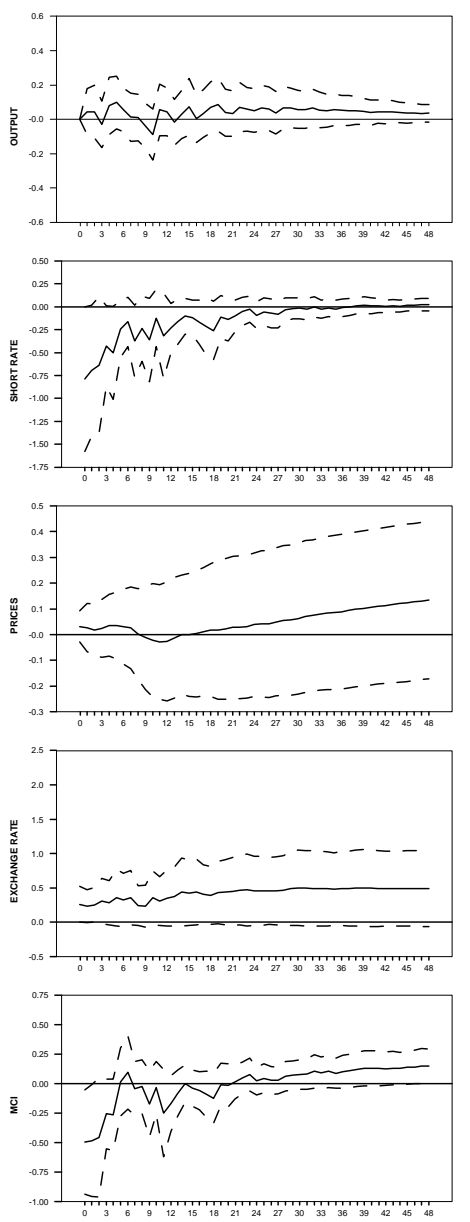

Italy
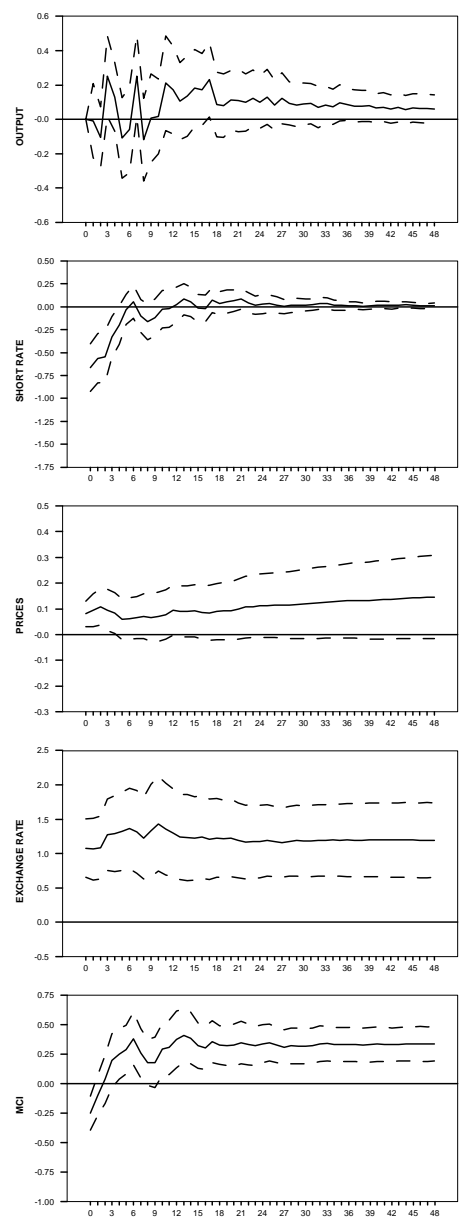

Germany
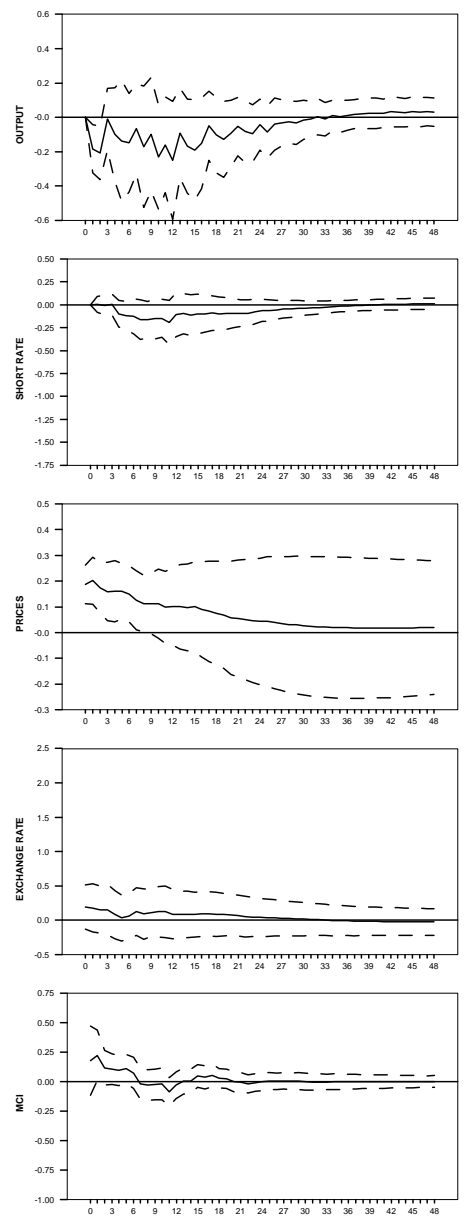

Note: The broken lines are bootstrapped 10\% confidence bands. The definition of the MCI is given in footnote 15 .

The results in Table 2 confirm this analysis. In France and Italy respectively, $43 \%$ and $64 \%$ of the exchange rate variability and $33 \%$ and $22 \%$ of the interest rate variability at the two-year horizon are attributable to foreign exchange market shocks. In contrast, in Germany the contribution of the exchange rate shocks to each of the endogenous variables at the two-year horizon is negligible.

The estimated effects of supply and demand shocks on output, prices and interest rates is very much in line with previous findings, such as those in Gerlach and Smets (1995). In each country a positive supply shock leads to a significant fall in prices and the nominal interest rate (Graph 4), 
while a positive demand shock has the opposite effect on prices and interest rates (Graph 5). The exchange rate effects of these shocks are generally insignificant. This is not very surprising for two reasons. First, the exchange rate effect of a supply or demand shock will depend on whether it is an idiosyncratic shock or a shock common to other European countries. In the latter, more likely case one would expect only limited exchange rate effects. Second, even if the estimated supply and demand shocks were idiosyncratic, the fact that the three countries were participating in the ERM would tend to limit the effects on the ECU exchange rate.

Graph 4

The effects of a supply shock

France
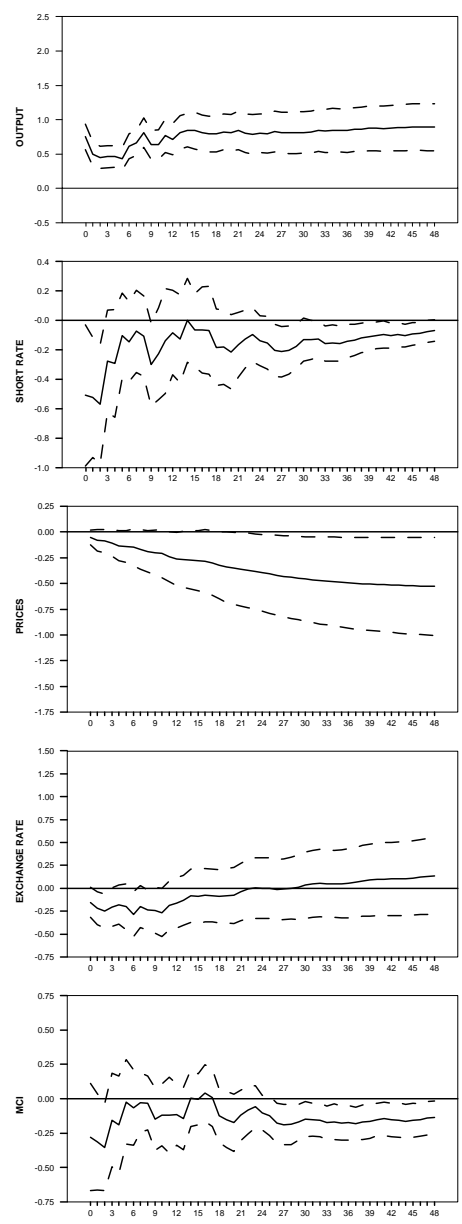

Italy
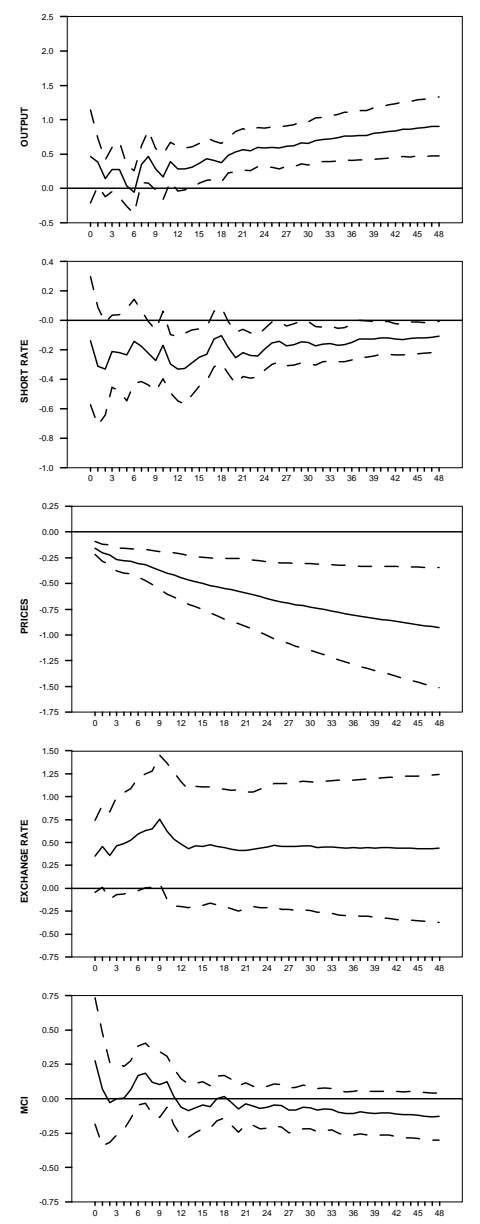

Germany
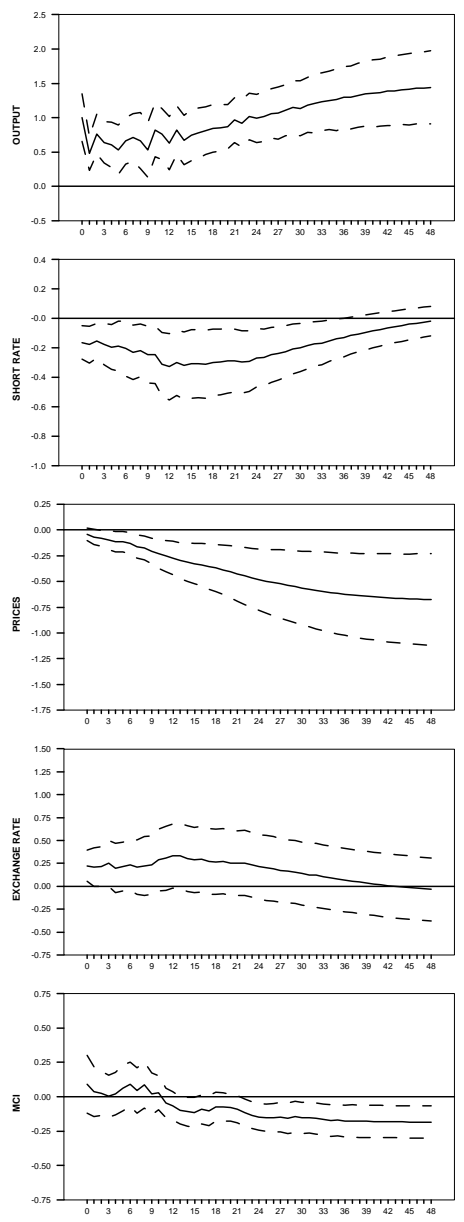

Note: The broken lines are bootstrapped $10 \%$ confidence bands. The definition of the MCI is given in footnote 15 . 


\section{Graph 5 \\ The effects of a demand shock}

France
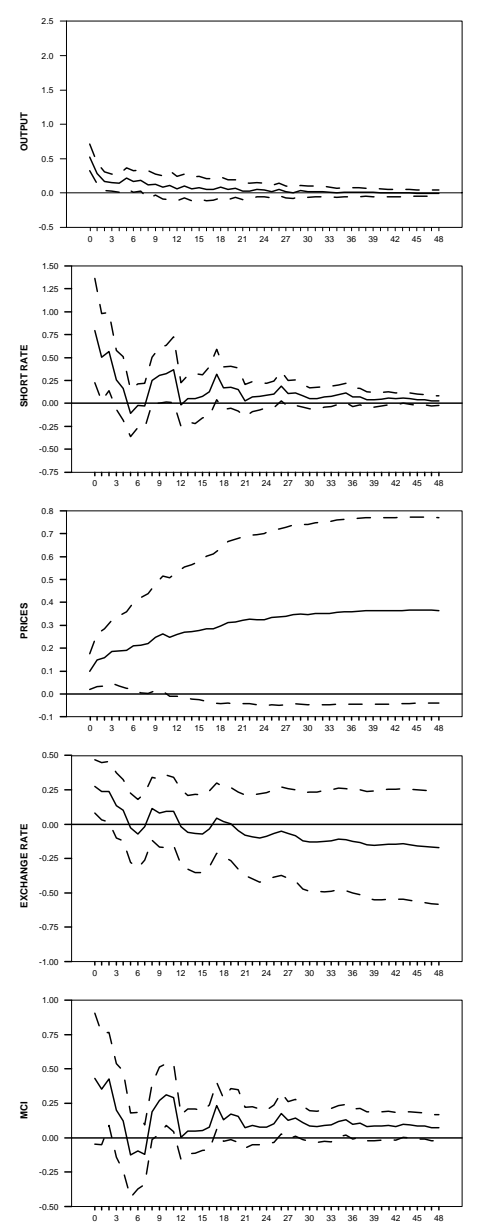

Italy
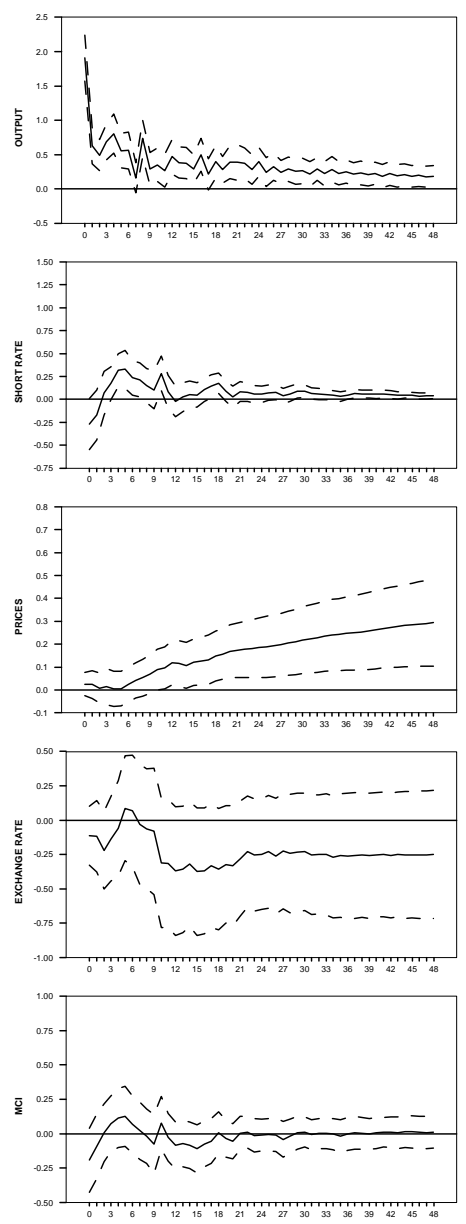

Germany
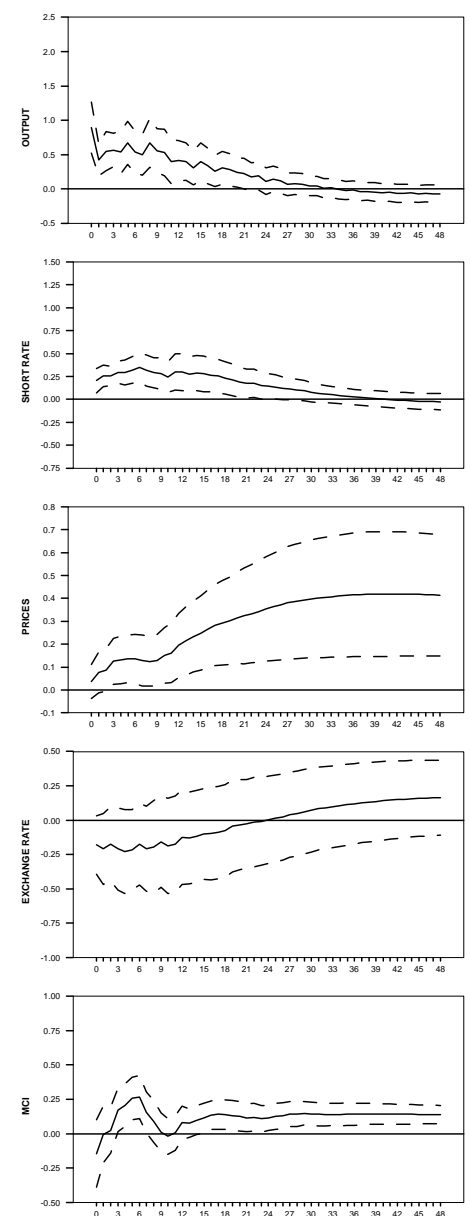

Note: The broken lines are bootstrapped 10\% confidence bands. The definition of the MCI is given in footnote 15 .

\section{Conclusion}

In this paper I have analysed the role of the ECU exchange rate in measuring monetary policy changes in France, Germany and Italy, three relatively open economies which have participated in the ERM since its inception in 1979. The main results of the analysis are twofold. First, I estimate the short-run weight on the ECU exchange rate in the monetary policy reaction function of these countries during the 1979-96 period and find, not surprisingly, that the weight on the ECU exchange rate is significant in both France and Italy, but not in Germany. In France, the weight has increased over the sample period and is not significantly different from one - as would be the case under pure exchange rate targeting - in the period since January 1987. In Italy, the weight estimated over the ERM period (1980:3-1992:8) is about one-half and therefore smaller than in France, partly reflecting 
the wider exchange rate band in the 1980s. However, in the most recent period starting in September 1992, when the Italian lira was forced out of the ERM, it has fallen to close to zero, which is consistent with a regime of interest rate targeting.

Second, following Smets (1996), I show how the estimated short-run weight on the exchange rate can be used in VAR analysis to solve the identification problem that arises from the simultaneous determination of interest rates and exchange rates. I analyse the estimated effects of a domestic monetary policy shock on output, prices, the short-term interest rate and the exchange rate and find that the qualitative effects conform to what one would expect in a standard open economy model. In particular, explicitly taking into account the different role of the exchange rate in the monetary policy formulation of these countries allows us to solve the so-called exchange rate puzzle which has been documented in Grilli and Roubini (1995).

\section{Appendix}

All data are in percentage logs, except the interest rates, which are in percentages. Output is measured by a monthly seasonally adjusted industrial production index. Prices are seasonally adjusted consumer prices. The nominal interest rate is the interest rate on three-month eurodeposits at the end of the month. The nominal exchange rate is the bilateral ECU exchange rate.

On the basis of ADF tests reported in Table A.1, I assume that in all countries output, prices and the exchange rate are integrated of order one, while nominal interest rates are stationary. Moreover, there does not appear to be an obvious cointegrating relationship between these variables. In particular, the unit root hypothesis for the real exchange rate cannot be rejected.

Table A.1

\section{Augmented Dickey-Fuller tests of a unit root}

\begin{tabular}{lccc} 
Series & France & Germany & Italy \\
\hline$\Delta \mathrm{y}_{\mathrm{t}}$ & $-8.0^{*}$ & $-13.5^{*}$ & $-16.2^{*}$ \\
$\Delta \mathrm{p}_{\mathrm{t}}$ & $-4.7^{*}$ & $-8.4^{*}$ & $-6.7^{*}$ \\
$\mathrm{R}_{\mathrm{t}}$ & $-4.9^{*}$ & -2.0 & $-4.8^{*}$ \\
$\Delta \mathrm{e}_{\mathrm{t}}$ & $-14.5^{*}$ & $-13.0^{*}$ & $-13.8^{*}$
\end{tabular}

Note: $*$ denotes significant at the $5 \%$ significance level. 


\section{References}

Barran, F., V. Coudert and B. Mojon (1996): "The transmission of monetary policy in the European countries". Document de travail, No. 96-03, CEPII.

Bernanke, B. and A. Blinder (1992): "The federal funds rate and the channels of monetary transmission". American Economic Review, No. 82 (September), pp. 901-21.

Bernanke, B. and I. Mihov (1995): "Measuring monetary policy". NBER Working Paper, No. 5145.

Christiano, L., M. Eichenbaum and C. Evans (1994): "Identification and the effects of monetary policy shocks". Working Paper WP-94-7, Federal Reserve Bank of Chicago, May.

Clarida, R. and M. Gertler (1996): "How the Bundesbank conducts monetary policy". NBER Working Paper, No. 5581.

De Grauwe, P. (1994): The economics of monetary integration, Oxford University Press.

Eichenbaum, M. and C.L. Evans (1995): "Some empirical evidence on the effects of shocks to monetary policy on exchange rates". Quarterly Journal of Economics, No. 110(4), pp. 9751009.

Freedman, C. (1993): "The use of indicators and of the monetary conditions index in Canada", in T.J.T. Balino and C. Cottarelli (eds.), Frameworks for Monetary Stability, Chapter 18, pp. 458476, International Monetary Fund, Washington, D.C.

Galí (1992): "How well does the IS-LM model fit post-war US. data?" Quarterly Journal of Economics, pp. 709-38, May.

Gerlach, S. and F. Smets (1995): "The monetary transmission mechanism: evidence from the G7countries". CEPR Discussion Paper, No. 1219.

Gerlach, S. and F. Smets (1996): "MCIs and monetary policy in small open economies under floating rates". Mimeo.

Giavazzi, F. and A. Giovannini (1989): Limiting exchange rate flexibility, MIT Press.

Grilli, V. and N. Roubini (1995): "Liquidity and exchange rates: Puzzling evidence from the G-7 countries". Mimeo. 
Grilli, V. and N. Roubini (1996): "Liquidity models in open economies: Theory and empirical evidence". European Economic Review, No. 40, pp. 847-859.

Grimes, A. and J. Wong (1994): "The role of the exchange rate in New Zealand monetary policy", in R. Glick and M. Hutchinson (eds.): Exchange rate policy and interdependence, Cambridge University Press.

Gros, D. and N. Thygesen (1992): European monetary integration, Longman, London.

Hansen, L.P. (1982): "Large sample properties of generalised method of moments estimators". Econometrica, No. 50, pp. 1029-54.

Kim, S. and N. Roubini (1995): "Liquidity and exchange rates: a structural VAR approach". Mimeo.

Smets, F. (1996): "Measuring monetary policy in the G7 countries: interest rates versus exchange rates". Mimeo.

Strongin, S. (1992): "The identification of monetary policy disturbances: explaining the liquidity puzzle". Working Paper WP-92-27, Federal Reserve Bank of Chicago (November).

Tsatsaronis, K. (1993): "Bank lending and the monetary transmission mechanism: the case of Germany". Mimeo. 


\section{Recent BIS Working Papers}

No.

27

May 1995

28

August 1995

29

September 1995

30

November 1995

31

December 1995

32

December 1995

33

January 1996

34

January 1996

35

July 1996

36

August 1996

37

September 1996

38

October 1996

39

January 1997

40

March 1997

41

May 1997
Title

The response of short-term bank lending rates to policy rates: a cross-country perspective

The term structure of Euro-rates: some evidence in support of the expectations hypothesis

The information content of the term structure: evidence for Germany

Money demand stability and currency substitution in six European countries (1980-1992)

Testing the quantity theory using long-run averaged cross-country data

The anatomy of the bond market turbulence of 1994

Derivatives and asset price volatility: a test using variance ratios

Monetary policy and the behaviour of interest rates: are long rates excessively volatile?

Varieties of monetary policy operating procedures: balancing monetary objectives with market efficiency

Estimation of speculative attack models: Mexico yet again

Does the term structure predict recessions?

The international evidence

International agreements in the area of banking and

finance: accomplishments and outstanding issues

Banking system failures in developing and transition countries: diagnosis and prediction

Monetary policy operating procedures industrial countries

The euro and European financial markets

\section{Author}

Claudio E.V. Borio and Wilhelm Fritz

Stefan Gerlach and Frank Smets

Stefan Gerlach

Renato Filosa

Stefan Gerlach

Claudio E.V. Borio

Robert N. McCauley

Benjamin H. Cohen

Stefan Gerlach

Joseph Bisignano

William R. Melick

Henri Bernard and Stefan Gerlach

William R. White

Patrick Honohan

Claudio E. V. Borio

Robert N. McCauley and William R. White 